\title{
QUANDO OS (DES)AFETOS "FAZEM FAMÍLIAS". NÃO-DITOS, MENTIRAS E FRACASSOS NAS TRAJETÓRIAS DE MIGRAÇÃO EM CABO VERDE
}

\author{
When (dis)affections "make families". \\ Unspoken, lies and failures in migration trajectories, Cape Verde
}

Andréa Lobo*

\begin{abstract}
Resumo. No presente artigo, pretendo complexificar o que venho chamando de "fazer família à distância" ao refletir sobre os segredos, os não-ditos, as mentiras, as manipulações e os fracassos que permeiam e constituem as relações sociais familiares entre aqueles que emigram e os que ficam. Minha intenção é perguntar o que podemos aprender sobre tais relações quando tomamos como ponto de partida não os laços de trocas, partilha e solidariedade, mas as formidáveis estratégias de manipulação de si e das experiências migratórias. O artigo explora como segredos, mentiras e omissões, alimentam o espaço social migratório no qual se atualizam as relações familiares. Indo além, abordarei como se dão aquelas trajetórias que, supostamente realizadas em prol do bem-estar de todos, muitas vezes levam ao sofrimento, às rupturas e ao abandono. Os dados que apresento são oriundos de pesquisas em duas ilhas, a Ilha da Boa Vista e a ilha de Santiago. Em ambos os casos estudei em contextos urbanos, respectivamente, na Vila de Sal-Rei e na Cidade da Praia (a capital do país).
\end{abstract}

Palavras-chave: migrações; segredos; mentiras; famílias; etnografia; Cabo Verde.

Abstract. In this article, I intend to complexify what I have been calling
"making a family at a distance" by reflecting on the secrets, the unspoken,
the lies, the manipulations and the failures that permeate and constitute
the family social relations between emigrants and those left behind. My
intention is to ask what we can learn about such relationships when we take
as a starting point not the bonds of exchange, sharing and solidarity, but the
formidable strategies for manipulating oneself and migratory experiences
that, through secrets, lies and omissions, feed the migratory social space in
which family relationships are updated. Going further, I will address how
those trajectories take place, which, supposedly made for the well-being of
all, often lead to suffering, ruptures and abandonment. The data I present

Universidade de Brasília, Departamento de Antropologia Social. Brasília, DF, Brasil. E-mail: andreaslobo@yahoo.com.br. Orcid: https://orcid.org/0000-0001-7525-1953. 
comes from research on two islands, Ilha da Boa Vista and Ilha de Santiago. In both cases I studied in urban contexts, respectively, in Vila de Sal-Rei and in Cidade da Praia (the capital).

Keywords: migrations; secrets; lies; families; ethnography; Cabo Verde.

Neste artigo pretendo refletir sobre os dinâmicas do "fazer família à distância" abordando os segredos, os não-ditos, as mentiras, as manipulações e os fracassos que permeiam e constituem as relações sociais familiares entre aqueles que emigram e os que ficam. Minha intenção é perguntar o que podemos aprender sobre tais relações quando tomamos como ponto de partida não os laços de trocas, partilha e solidariedade, mas as estratégias de manipulação de si nas experiências migratórias que, por meio de segredos, mentiras e omissões, alimentam o espaço social migratório no qual se atualizam as relações familiares. Indo além, abordarei como se dão aquelas trajetórias que, supostamente realizadas em prol do bem-estar de todos, muitas vezes levam ao sofrimento, às rupturas e ao abandono.

Como expresso no título, meu ancoramento etnográfico é a sociedade crioula de Cabo Verde ${ }^{1}$. No contexto de uma antropologia da migração, esta nação insular da África Ocidental é um caso excepcional, pois sua vida social tem sido moldada pela mobilidade e pelas redes transcontinentais desde que os comerciantes portugueses lá se estabeleceram. A mobilidade, os fluxos comerciais de coisas, pessoas e valores; e não o sedentarismo, são o que tem garantido o acesso à continuidade social em Cabo Verde durante muitos séculos.

Minha análise se baseia em material etnográfico resultante de pesquisa de longa duração em Cabo Verde. Nos últimos 15 anos tenho me dedicado ao estudo das dinâmicas familiares no arquipélago e suas relações com as mobilidades e movimentos que marcam as vidas de meus interlocutores, sendo o fluxo migratório uma faceta central. Os dados que aqui apresento são oriundos de pesquisas em duas ilhas, a Ilha da Boa Vista e a ilha de Santiago, em ambos os casos estudei em contextos urbanos, respectivamente, na Vila de Sal-Rei e na Cidade da Praia (a capital do país). Meus lugares de pesquisa são as casas e minhas interlocuções são sobretudo com mulheres, crianças,

1 O arquipélago de Cabo Verde situa-se na costa ocidental africana. Trata-se de um pequeno país insular com suas 10 ilhas (9 habitadas) que abrigam uma população de cerca de 500 mil habitantes. A moderna sociedade crioula de Cabo Verde é resultado do achamento das ilhas desabitadas por Portugal e sua posterior colonização. O povoamento das ilhas se efetiva no contexto do tráfico negreiro, formando-se uma sociedade escravocrata e mercantil. Produto de contatos intensos, profundos e duradouros, marcados por uma desigualdade de poder entre uma classe dominante de colonizadores europeus e uma classe dominada composta por povos africanos de origens variadas oriundos do continente, nasce essa sociedade crioula (Trajano Filho, 2009). 
jovens e idosos, ou seja, aqueles que habitam, animam e dão vida às casas enquanto espaço de pertencimento.

Desde o início do percurso seguindo essas famílias móveis minhas questões se dirigem para aqueles que vivem nas ilhas: os que vivenciam as migrações sem partir, aqueles que vêm e vão; os que já foram e regressaram ou que esperam ir. Seguir pessoas em fluxos a partir de um lugar fixo, as casas, as ilhas, o país, é o que tem me permitido incorporar experiências diversas e perspectivas que se complementam em um entretecer de partidas e regressos que constituem e são constituídas nos seios das famílias em seu constante (des)fazer-se.

\section{Famílias e cuidados transnacionais}

Os interessantes debates sobre a diversidade de trajetórias e de relações de poder que a categoria migrante encerra resultaram na incorporação do gênero (e não só) para o centro dos estudos das dinâmicas migratórias. Certamente tal movimento não está desconectado do advento do crescente número de mulheres que emigram de forma autônoma e independente (e não em um contexto de reunificação familiar, seguindo o companheiro que foi) desde meados do século XX. É nesse contexto que ganha relevância no início dos anos 2000 não só uma literatura sobre mulheres migrantes, mas a temática das dinâmicas familiares nesses contextos. Termos como famílias espalhadas, famílias à distância, crianças do mundo global começam a circular pelos estudos e se assenta no campo o termo família transnacional - passando a sintetizar aqueles contextos relacionais que mantém unidos os parentes e familiares apesar da distância física².

A pergunta é essencialmente etnocêntrica: como vivem, como se reproduzem os sentidos de família nesses contextos? Como manter os laços duradouros que caracterizam as relações familiares à distância? Como se atualizam pertencimentos, afetos, reciprocidades em situações de separações prolongadas no tempo e no espaço? Que estratégias são essas que permitem a manutenção dos laços familiares? Como é fácil perceber, tais questões partem de noções de família ou noções de normalidade que, no mínimo, pressupõem que o estar juntos é uma condição do ser e ter família.

Os estudos que são enquadrados nessa rubrica, "famílias transnacionais", constituem hoje um arcabouço interessante de etnografias que nos fornecem uma cartografia das estratégias, dilemas, desafios que permeiam tais contextos. Em uma síntese rápida, o argumento é de que, sim, famílias conseguem ser famílias nessas situações graças ao universo de reciprocidade, cuidado mútuo

\footnotetext{
2 Ver: Basch et al., 1992; Bryceson, Vuorela, 2002; Chamberlain, 2003, 2009; Chamberlain, Leydesdorff, 2004; Glick Schiller, 2003; Parreñas, 2005.
} 
e solidariedade que se tece em uma complexa rede de relações que ultrapassa fronteiras nacionais. É em um diálogo crítico com esse campo que podemos inserir minhas pesquisas em Cabo Verde. Explico-me.

Primeiramente, de um ponto de vista teórico, as noções de família e cuidado transnacional são baseadas em um ponto de vista muitas vezes confinado ao "presente do pesquisador em seu campo". Como bem afirma Laurent (2018), essa posição metodológica direciona a pesquisa e restringe a possibilidade de dar uma explicação mais ampla dos movimentos que estruturam essas famílias ao longo de várias gerações, mas também dos processos subjacentes à unidade dos núcleos dispersos pelos continentes (Laurent, 208, p. 160), uma unidade que tenho denominado de "campo social migratório" ${ }^{3}$. Portanto, se ampliamos a lente metodológica para além do presente e incorporarmos uma perspectiva processual perceberemos, por exemplo, que em sociedades como a cabo-verdiana, deslocamentos migratórios são apenas uma faceta de um complexo de mobilidades que permeiam as vidas dos ilhéus (Lobo, 2012b; Vasconcelos, 2012).

Minha segunda consideração tem a ver com os pressupostos que baseiam as adjetivações ao conceito de família. Ainda que reconhecendo os avanços nas teorias sobre as dinâmicas migratórias trazidas pelos estudos sobre transmigrantes e seus desdobramentos nas análises das trajetórias familiares, minha posição advém da dificuldade em aderir a teorias que criam "tipos" familiares pelo uso de adjetivos. Em minha concepção, quando teóricos adjetivam famílias, parecem concordar que há, em algum lugar, uma família que não carece de adjetivos enquanto as demais precisam ser qualificadas. Como consequência, as ditas famílias transnacionais aparecem como "fora de lugar", em meio a traumas e dilemas que a transnacionalidade e o distanciamento às impõem. Conflitos, culpas, oportunidades, afetos são marcas das relações familiares, certamente o distanciamento físico e temporal tem suas especificidades que devem ser por nós analisadas, mas sempre à luz das experiências dos indivíduos e dentro de seus contextos, e não por meio de modelos familiares alternativos que supõem nas entrelinhas a existência de um modelo de normalidade. Entendendo, portanto, que o distanciamento das famílias cabo-verdianas é uma condição e não um estado, e que estas se reproduzem a partir de uma

\footnotetext{
Utilizo a noção de "campo social migratório" inspirada nos termos de Bourdieu (1980) quando chama nossa atenção para as maneiras pelas quais as relações sociais são estruturadas pelo poder. Os limites de um campo são fluidos e o próprio campo é criado pelos participantes que se juntam em suas lutas por posição social. Segundo o autor, indivíduos ou instituições compõem as redes que conformam o campo se vinculando e disputando posições sociais. Tal noção vem sendo utilizada nas teorias sobre transnacionalismo visto que uma das vantagens em falar de "campos sociais" é a de que o foco recai nas relações entre pessoas e locais que configuram a rede, e não no movimento geográfico. Para aprofundar essas questões, ver: Glick Schiller, Fouron, 1999; Glick Schiller, 2003; Levitt, Glick Schiller, 2004.
} 
diversidade de fluxos, opto por uma expressão que mais se aproxima de meu contexto etnográfico, a de "famílias à distância" (Lobo, 2014a).

É com tal perspectiva que proponho abordar projetos migratórios que são compreendidos localmente pela chave do fracasso. O que pretendo é colocar no centro da análise uma dimensão que está presente em diversos trabalhos, mas quase sempre em segundo plano analítico: os não ditos, as mentiras, os segredos e os conflitos em trajetórias migratórias.

É necessário salientar que tais classificações advêm de meus interlocutores de pesquisa, que avaliam determinadas trajetórias pela chave do sucesso e do fracasso a partir de um contexto relacional que especifica o que é adequado ou não nas interações entre os que partiram e os que ficaram. Como argumentam West \& Fenstermaker (1995), as classificações de pessoas e fenômenos não advêm de atributos individuais, mas são realizadas nas interações. Sendo assim, os membros das sociedades caracterizam as atividades de maneira a nomeá-las, descrevê-las ou reconhecê-las, inserindo-as em uma estrutura social que fornece os elementos para as avaliações de condutas e comportamentos (West, Fenstermaker, 1995, p. 21). Ao refletir sobre projetos migratórios pela via dos segredos, mentiras e fracassos a minha questão não é sobre a conformidade ou o desvio nas trajetórias, mas seu processo de avaliação e as consequências desta para as interações entre familiares ${ }^{4}$.

Com tais questões em mente, sigo no esforço de refletir sobre projetos interrompidos, casos conflituosos e suas lógicas de reciprocidade que, essa é minha hipótese, mantem as pessoas relacionadas. Ao final do artigo a questão sobre os limites e possibilidades de reprodução familiar em contextos migratórios se recolocará: se conflitos alimentam as relações à distância tanto quanto os afetos, qual seria esse difícil equilíbrio nas relações que, em algumas situações, faz com que a rede familiar se desagregue?

\section{Sobre ilhas $\mathrm{e}(\mathrm{m})$ fluxos}

A sociedade cabo-verdiana tem como uma de suas marcas identitárias a emigração. Marcado desde sua origem por fluxos e movimentos, ainda no período colonial, para além dos fluxos mercantis o país desenvolveu uma dinâmica migratória de duplo caráter, espontânea e forçada. No primeiro caso, a origem pode ser traçada nas conexões com a América do Norte que surgem durante o comércio de escravos e que são consolidadas no início do século XIX

\footnotetext{
4 Mesmo porque, como assinalam as autoras, ao focar nas interações estamos abertos a perceber como elas dão espaço para a mudança e a reinterpretação de significados (por exemplo, o que é apresentado como segredo em uma interação pode ser apresentado de outra forma em outra). Agradeço ao parecerista da REMHU por me apresentar a teoria sobre doing gender e doing difference (West, Fenstermaker, 1995).
} 
com navios baleeiros de New England que faziam paradas em Cabo Verde e contratavam homens jovens para trabalho nos barcos.

Estes aproveitavam a oportunidade para emigrar para os Estados Unidos, abrindo uma rede migratória que, ainda hoje é a preferencial em diversas ilhas do arquipélago (Carling, 2001; Meintel, 2002). No caso da emigração forçada, esta ocorre por volta dos anos de 1970, quando os colonizadores portugueses transportam centenas de cabo-verdianos para São Tomé e Príncipe para o trabalho nas roças de café e cacau (Carreira, 1983). Com o tempo os percursos migratórios vão se diversificando prioritariamente para países da Europa, levando à tal configuração que nos permite afirmar que a emigração é um fator estruturante nesta sociedade (Carreira, 1983; Carling, 2002; Trajano Filho, 2009; Vasconcelos, 2012; Lobo, 2014a; Laurent, 2018; Defreyne, 2016).

A emigração traçada por diversos destes autores é marcadamente masculina. De acordo com o projeto migratório familiar, cabe ao homem a busca por uma melhoria de vida para toda a família, seja por meio do envio de recursos financeiros e bens seja pela responsabilidade em dar continuidade ao projeto migratório viabilizando a ida de outros parentes. A mulher que fica é descrita na literatura como uma mulher que espera (Braz Dias, 2000; Monteiro, 2013; Veiga, 2013).

Minha pesquisa na Ilha da Boa Vista no início dos anos 2000 vem adensar esse quadro, uma vez que analisei um contexto muito particular no arquipélago, o de uma comunidade em que quem sai para a emigração em direção à Itália são as mulheres, fluxo que se inicia nos anos 1960 e, com altos e baixos, tem continuidade desde então. Minhas questões complexificavam a máxima da mulher que espera e as disputas de poder entre homens e mulheres em uma sociedade patriarcal e matricentrada, as conclusões foram no sentido de que a migração feminina tanto transforma cenários quanto opera nos processos de reprodução social das dinâmicas familiares locais (Lobo, 2010, 2011, 2012b, 2014a).

À época adentrei pelas famílias, pois pensava ser importante inserir os projetos migratórios no universo das relações de parentesco. Nesse sentido, minha principal linha interpretativa era a de que a distância espacial não necessariamente diminui a efetividade das relações de parentesco, ou seja, a proximidade ou a intimidade na esfera familiar cabo-verdiana estaria menos ligada às noções de tempo e espaço do que à efetividade da comunicação e da reciprocidade das interações e dos cuidados entre membros da família. E como isso se atualiza? Por meio de um complexo sistema de troca de bens materiais, dinheiro, informações e pessoas em uma rede de alta dinamicidade que mantem as pessoas conectadas em torno de um projeto coletivo que faz circular o capital migratório (Laurent 2018; Lobo, 2014b). 


\section{Partilhando segredos e mentiras, alimentando conflitos}

E quando esse complicado esquema falha? Essa é a questão que me instiga neste artigo. Se é certo que as estratégias de manutenção de proximidade à distância operam com relativo sucesso, isso não se dá sem conflitos, dilemas e rupturas. A partir de minhas pesquisas, os exemplos são inúmeros e diversos, podendo ser classificados em diferentes tipos.

Desvios das rotas em que coisas e informações circulam. Como analisei anteriormente (Lobo, 2014b) as trocas de encomendas, bens materiais e dinheiro são centrais nas relações entre os que foram e os que ficaram. Nesse contexto, são muitas as histórias de emigrantes que alegam ter enviado dinheiro, encomendas, presentes por portadores, mas esses nunca chegaram às mãos dos destinatários. Um dos casos dramáticos que tenho em meus dados é o de uma emigrante na França que afirma que enviava sistematicamente dinheiro para a construção de sua casa para o responsável pela obra, seu companheiro, mas esta não chegou a ser concluída. Segundo os rumores ele teria "bebido todo o dinheiro da pobre mulher que estava no sacrifício do trabalho na emigração". O homem se defende alegando que as remessas não chegavam - ou ela não teria enviado, ou teria ficado pelo caminho nas "mãos de gente". Essa história envolve ao menos três famílias que romperam relações devido aos conflitos e acusações mútuas sobre os recursos supostamente enviados e não recebidos. Esse breve exemplo é permeado de histórias mal contadas, versões e disputas que colocam todos os envolvidos sob suspeita. Um ponto a ressaltar é o da complexidade dessa trama das redes de trocas entre Cabo Verde e sua diáspora, uma rede que depende não só do emissor e do receptor, mas envolve um terceiro, o portador (Lobo, 2014b; Defreyne, 2016) ${ }^{5}$.

Outro conjunto de eventos que permeiam esse cenário é o que podemos chamar do jogo entre expectativa e realidade. É recorrente nos estudos migratórios, e não é diferente em Cabo Verde, o universo dos não ditos e mentiras que alimentam a construção do status de emigrantes e também dos que ficaram, que com frequência aumentam ou inventam sobre a boa situação dos parentes lá fora - observemos os relatos a seguir:

Há muitas moças que trabalham mesmo, mas há também muitas delas que chegam lá, arranjam seus movimentos e vivem sustentadas por homens, chegam aqui e ficam dando show que são muita coisa e que estão bem por lá, mas qual é? (Conversa com emigrante em férias, Boa Vista, 2005)

\footnotetext{
Essa forma de enviar e receber coisas e dinheiro por meio de portadores é interessante, pois há inúmeras possibilidades disponíveis no mercado migratório para fazer tais objetos circularem: correios, bancos, transferências on-line no estilo Western Union, transporte de cargas etc. Todas essas formas são amplamente utilizadas pelos cabo-verdianos, entretanto, a figura do portador não perde a centralidade, sendo o envio de encomendas por meio de terceiros uma prática que faz relações nessa intrincada rede.
} 
Por muito tempo me perdi por lá, a verdade é que não consegui os papeis, nos trabalhos que consegui fui enganada, os patrões não pagavam correto e nem pagavam os benefícios que eu tinha direito, mas a cobrança aqui era grande demais... eles acham que lá estamos bem, com muito dinheiro, numa vida boa... e dá muita vergonha dizer que não... até um momento que não aguentei mais tanta pressão... tive que voltar e foi muito difícil, voltei sem nada... foi muita vergonha porque eu não podia contar quando estava lá... mandava fotos de lugares bonitos e todos achavam que eu estava bem, mas na verdade estava muito mal... foi tudo uma ilusão e agora estou aqui, pior do que antes. (Conversa com uma ex-emigrante, Boa Vista, 2005)

Em outro momento, tive a oportunidade de presenciar um diálogo interessante na Cidade da Praia - estávamos em uma pequena festa na casa de uma amiga e, de surpresa, chegou o Bruno. Ele havia emigrado para os EUA e pela primeira vez voltava de férias. Bruno antes de emigrar era funcionário do Banco de Cabo Verde, me disse que emigrou não por necessidade, mas porque estava cansado das ilhas e queria melhores oportunidades fora. Claro que, desde o momento de sua chegada, Bruno virou o centro das atenções na festa. Todos queriam saber de sua experiência, dos amigos e familiares que estavam lá, de sua vida. Ele falou de como Boston era um lugar bacana, de sua rotina, dos amigos, do muito trabalho e da falta de tempo para lazer. Seu relato por vezes assumia um tom de autoridade quando comparava um "aqui" e um "lá" que marcava a oposição entre os dois universos - "atenção, lá não é como aqui que as pessoas têm tempo para se divertir, não fazer nada, falar da vida dos outros, lá não há tempo, é tudo rápido, é só trabalho".

Sua fala buscava equilibrar a exaltação de sua vida lá fora e a dimensão do sacrifício da vida de emigrante. Contou sobre sua casa, seus ganhos financeiros e seus projetos de futuro, mas em nenhum momento falou ou foi questionado sobre seu trabalho. Curiosa, perguntei, "mas o que você faz lá" - todos me ignoraram e engataram outro assunto. Insisti na pergunta e novamente fui ignorada. Para não me tornar inconveniente, me calei! Depois voltei ao tema com minha amiga e sua resposta foi: você acha mesmo que ele ia dizer o tipo de trabalho que faz lá? (Diário de campo, Praia, 2015).

Um último exemplo vem mostrar como essas práticas não têm um caráter unidirecional, sendo também uma estratégia de quem ficou.

Um dia cheguei na casa de D. Teodora e ela estava aflita, pois uma de suas filhas chegaria da França no dia seguinte. Essa era uma de suas filhas de grandeza (querida, preferida), filha emigrante que sempre telefonava, enviava recursos e presentes para "facilitar a vida da mãe nas tarefas de casa". Assim que cheguei D. Teodora me levou em seu quarto e me pediu ajuda para desencaixotar alguns eletrodomésticos: liquidificador, batedeira, multiprocessador, aspirador de pó, sanduicheira, máquina de café. Sua preocupação era de que a filha se chateasse com o fato dela nunca ter usado os presentes. Ela me explicou: "eu 
nem sei usar essas coisas, não tenho jeito para isso! Prefiro fazer as coisas do meu jeito". Por outro lado, não queria desagradar a filha. Desencaixotamos tudo e arrumamos a cozinha com os eletrodomésticos expostos. Diga-se de passagem, que essa cozinha nunca era usada, pois as atividades de D. Teodora eram realizadas no quintal. Se a filha se convenceu? Ela percebeu de imediato o cenário que montamos, não se chateou diretamente com a mãe, mas os dois meses de férias que passou em Cabo Verde foram marcados por inúmeros conflitos entre ela e os irmãos que ficaram nas ilhas. Estes a acusavam de "se achar" melhor do que eles, de querer mudar toda a rotina e a vida da mãe nos dois meses que lá estava, de "dar show" (se exibir), de gastar o dinheiro em supérfluos no lugar de enviar aos filhos (criados pela avó) (Diário de campo, Boa Vista, 2004).

O que desejo extrair desses exemplos é uma reflexão sobre esse conjunto de histórias mal contadas, mal-entendidos, mentiras, segredos e conflitos que também circulam nesses espaços sociais que extrapolam o local. A questão é: e nos casos em que omitir fatos ou mentir faz parte do jogo? Sendo inclusive esperado ou defensável que, em dadas circunstâncias, um parente aqui ou lá minta ou omita algo em nome da manutenção do status do coletivo ou do seu próprio? É Simmel (1964) quem nos lembra que os segredos e as mentiras envolvem toda uma dinâmica comunicativa feita de retóricas, transparência, opacidade, cooperação, confiança e, em certa medida, revelação. Para o autor sem tais elementos, que se refletem em atitudes, seria difícil viabilizar as relações sociais. Além disso, como segredos e mentiras dizem muito sobre quem fala, não se pode pensá-los sem considerar o contexto, pois eles não são pura negatividade (Teixeira, 2014, p. 40) ${ }^{6}$.

Os segredos, seja na ordem do escondido (não dito, silêncio, omissão) seja na ordem do mascarado (mentira, dissimulação) fazem parte da dinâmica social, surgem como ação de dissimular as realidades através de meios negativos e positivos possibilitando o alargamento da vida social. Para Simmel, eles oferecem a possibilidade de um segundo mundo junto com o mundo do manifesto, sendo este decididamente influenciado por aquele. Esse jogo de ocultação e revelação cria relações e produz comportamentos próprios, de modo que as relações estabelecidas poderão ocorrer justamente por haver algo que os une, que os mantêm envolvidos através de uma conexão social que os distingue e denuncia mutuamente (Viana, Sousa, 2015, p. 22).

Para os casos apresentados aqui, as histórias sobre as experiências migratórias acabam por esconder e revelar os mundos do lado de lá e do lado

\footnotetext{
${ }^{6}$ No fascinante artigo "A sociologia do segredo e das sociedades secretas" Simmel afirma: "Devemos ter cuidado para não nos deixarmos enganar pela valoração eticamente negativa da mentira e pela significação socialmente positiva e direta da ausência de verdade na conformação de certas situações" (Simmel, 2009[1964], p. 225).
} 
de cá que são vividos à distância, mas em simultaneidade. Tal jogo de revelação, ocultação e distorção dos mundos parece fortalecer conexões e acabam por reproduzir dinâmicas familiares locais, permeadas também por conflitos, afetos e desafetos.

Afirmar que conflito, segredo e mentira são formas de relações sociais não é novidade para os cientistas sociais. Muito menos é desconhecido o fato de que migrantes dissimulam ou omitem sua situação por vezes dramática alhures. Por sua vez, é perfeitamente esperado que os familiares que ficaram na terra natal se utilizem de estratégias semelhantes para participar dos benefícios materiais e simbólicos de ter na família um emigrante.

O que talvez minha reflexão tenha a acrescentar é que se falar do cuidado e do afeto em redes transnacionais faz sentido para compreendermos as estratégias para manutenção e reprodução social em sociedades como Cabo Verde; faz-se necessário compreender esse contexto de reciprocidade em todas as suas dimensões. Resgatando Simmel (1964), é trazer para o centro da análise que sem este segundo mundo criado pelo escondido e pelo mascarado tais redes transnacionais seriam de difícil viabilização. Nesse sentido, a especulação sobre o mundo do outro encontra terreno fértil nos contextos de migração, pois estes permitem que imaginação e fantasia criem asas - sendo alimentadas por atores como Bruno que, ao contar sobre seu mundo nos EUA, aumenta, inventa, omite e ressalta. O escondido e o mascarado, portanto, são parte do jogo e, mais do que isso, são centrais para que ele continue sendo jogado.

Porém, as estratégias do que dizer, não-dizer ou distorcer devem ser bem utilizadas, pois, o interesse maior é o da manutenção e circulação do capital migratório em seu sentido coletivo e individual. Tal como abordado na literatura sobre migração, o sucesso dos retornados e dos migrantes estimula a imaginação popular (Appadurai, 1996). Lydie Moudileno (2001), ao analisar o belo romance de Alain Mabanckou "Bleu, blanc, rouge"7, propõe pensar a emigração não somente como um projeto circular (dentro do qual circula um capital migratório), mas como construção de imaginários, da emigração sendo elaborada e vivida como uma ficção. É nesse contexto que são utilizadas as estratégias de manipulação de si, das experiências e dos lugares em uma ficção que, se bem-sucedida, tem assento em um cenário real e cujo resultado deve, logicamente, ser o retorno triunfante para o país (Moudileno, 2001, p. 183).

Tais narrativas não se dão somente no discurso, mas nas performances e nos corpos. Portanto, o envio de coisas e recursos, a qualidade do que é

O romance tem como protagonista o jovem congolês Massala-Massala que, influenciado por um ancião de sua comunidade, parte para a França. Após desilusões e confusões, ele é preso e, na sequência, deportado pelas autoridades francesas, tendo que retornar ao seu país. O romance se inicia com o jovem no avião, refletindo sobre o fracasso de seu empreendimento (Moudileno, 2001). 
enviado, o compartilhar de notícias e de imagens e os retornos periódicos (em férias) são indispensáveis para se encenar o potencial de metamorfose (física, social e cultural) inerente ao movimento migratório e garantir o sucesso dos projetos.

O que os relatos aqui apresentados chamam atenção é para o fato de que a imagem de sucesso é constantemente nuançada e colocada em risco por aqueles que falham nesse esquema e revelam as misérias materiais e morais da experiência migratória. A afirmação de que "a vida no estrangeiro é uma ilusão" talvez seja a expressão máxima do que estou querendo abordar, uma vez que enquadra os inúmeros casos daqueles que não conseguem gerir expectativas e realidades das redes de reciprocidade, daqueles que vivem o drama do retorno sem sucesso, daqueles que retornam carregando em seus corpos as marcas do fracasso.

A partir das trajetórias de meus interlocutores, percebo que as mentiras, omissões e não-ditos operam no sentido de construir uma imagem de si e do outro que equilibre demandas e expectativas de tal forma que sair siga sendo um sonho sonhado por muitos, mas que o regressar desiludido também possa ser uma possibilidade no campo de interações. Por meio das imagens nuançadas das expressões "o estrangeiro é uma ilusão" e "a vida de emigrante é um sacrifício" criar-se-ia um espaço social que tanto incorpora os sucessos quanto os fracassos.

Me resta, ainda, uma última questão. Após propor a ampliação do universo relacional do cuidado para o conflito como um dos elementos que une pessoas e mundos fisicamente distantes, quero avançar em uma dimensão mais radical. Se fracassos, conflitos e os subsequentes dramas que deles decorrem não rompem relações, quando essas se romperiam?

\section{Sobre rupturas, fracassos, abandonos}

Para refletir sobre tal questão apresento uma trajetória permeada por dor e marcada pela ruptura de laços. A história de Antônia e Federica, sua filha, é classificada por elas mesmas como um exemplo de "fracasso". Tal noção reflete não somente as dificuldades por quais elas passaram, mas sobretudo suas consequências, quais sejam, a impossibilidade da manutenção e continuidade dos vínculos com sua comunidade de origem.

Reproduzo a história destas duas mulheres pelas mãos do trabalho de Claudia Bongianino (2012, p. 163). Antônia foi para Nápoles com contrato de trabalho em 1980, quando tinha 26 anos, deixando uma filha (Maria) de um ano de idade, sob os cuidados de sua mãe. Na Itália ela começou a se relacionar com o pai de sua segunda filha, Federica, que nasceu na Itália e lá 
viveu com a mãe por toda a vida. Maria, a filha nascida e deixada em Cabo Verde, nunca foi se juntar à Antônia.

Antônia foi empregada como doméstica em algumas casas e afirma ter sido tratada "como escrava". Sem ter direito à alimentação adequada, dias e horários de folga e com uma criança pequena (Federica) para criar, ela continuou no emprego até ficar doente. Desempregada e em recuperação médica, Antônia não conseguiu ter acesso ao auxílio-doença, pois veio a descobrir que o patrão não pagava sua contribuição para ter acesso aos serviços do Estado. O processo de regularização de sua situação foi demorado e, como consequência, Antônia e Federica viveram na Itália clandestinamente por dois anos.

Este intervalo de tempo foi suficiente para complicar o acesso de ambas aos direitos, pois com a perda do emprego e o não pagamento de seus direitos pelo patrão, Antônia perdeu sua Permissão de Estadia (passando ao status de clandestina ou ilegal), e consequentemente, o direito aos benefícios para o tratamento de sua saúde frágil. Por sua vez, Federica, apesar de ter nascido e vivido toda a sua vida na Itália, encontrava-se em situação irregular, pois os dois anos de clandestinidade a impediam de requerer a cidadania italiana. Com poucos recursos econômicos, sem conseguir manejar essa situação e vivendo em um relativo grau de isolamento, mãe e filha se ajudavam como podiam para criar duas crianças, filhas de Federica.

Bongianino (2012) conclui que tanto Antônia quanto Federica não conseguiram alimentar uma rede de relações e de apoio, nem na Itália nem em Cabo Verde. Com isso, nem voltar para sua terra natal se colocava como opção. Em Cabo Verde, essa passou a ser uma não-relação, uma triste lembrança de mais uma filha, mãe ou parente que partiu para o estrangeiro e esqueceu dos que ficaram. Tudo isso leva a autora a concluir que "houve uma falha na estratégia migratória familiar de Antônia e ela encontra dificuldades para manter e criar relações emocionais com Cabo Verde, inclusive com seus pais e sua filha mais velha, que vivem no arquipélago" (Bongianino, 2012, p. 170).

Como já sinalizado aqui, há vários fatores, em um processo migratório, que são fundamentais para que os vínculos sejam cultivados. Em um nível mais estrutural, é importante que a emigração seja um affair de família, ou seja, espera-se que a partida gere retorno para todo o grupo familiar. Nesse sentido, é fundamental que novas pessoas sejam chamadas ou levadas para a emigração, além dos envios e contatos regulares.

Entretanto, Antônia não foi capaz de alimentar esta rede e de dar continuidade a um projeto migratório que se perdeu no decorrer dos anos. A autora não nos conta sobre as condições em que se deu esta ruptura, mas foi 
possível complementar, em minha pesquisa em Cabo Verde, que a trajetória de Antônia é classificada pela família que ficou pelos signos da ingratidão e do abandono. Em conversa com um membro de sua família, ele afirma: "Ela foi para a Itália há muitos anos e nunca mais veio, nem dá notícias. A filha que ela deixou foi criada pela avó e nem conhece a mãe. Ela nem liga para a filha no aniversário ou no natal. É triste, mas não é só na nossa família que tem isso, ingratas, são isso que elas são... a situação que ficou minha mãe... você sabe..." (Praia, 2015).

Ingratidão e abandono são as categorias empregadas pelos meus interlocutores de pesquisa quando se referem aos emigrantes que não respondem às expectativas acima descritas e que, em suas palavras, "esquecem" ou "abandonam" suas famílias que ficaram. E assim chego a um esboço de resposta à minha questão sobre as rupturas: seria pela ausência de circulação que projetos familiares se rompem e relações se desfazem.

Veiga (2013) reflete sobre o abandono na perspectiva de mulheres cujos maridos emigraram e desapareceram em terras europeias ou norte americanas. No contexto rural da ilha de Santiago essas mulheres são conhecidas como "viúvas do lenço branco", ou viúvas de maridos vivos, e suas histórias de abandono são dramáticas. Tal cenário é complementado pelo filme de Pedro Costa que nos apresenta Vitalina Varela, uma dessas mulheres que tem sua trajetória marcada pela dor do abandono e pelo rompimento dos laços de reciprocidade por parte do marido que emigrou para Portugal e nunca voltou. Em uma verdadeira crônica da ausência a atriz-personagem revive, no monólogo com o espírito de seu marido morto, a dor dessa ruptura.

Um dia você fugiu para Portugal e não disse nem até logo! Eu voltei para casa, fiz comida, e fiquei com ela na panela... até que joguei no lixo. Você andou por todo beco de Lisboa (...) atrás de toda mulher de rua, igual bode quando sai do curral. Quando eu escrevi uma carta para você pedindo ajuda de dinheiro, você nem respondeu, ficou quieto. Quando você foi embora, eu trabalhei duro. (...) Mas você nunca soube disso. Você nunca entrou na nossa casa depois que ela estava terminada, toda pintada. Você falava, "eu vou já, eu vou já"... até que você morreu e nunca foi. (...) A sua morte não pode apagar todo o mal que você fez. Você não pode fugir mais. (Vitalina Varela, filme de Pedro Costa, 2019, tradução minha)

Lévi-Strauss, ao se referir à tese de Mauss sobre a troca como meio de se opor sem se massacrar, afirma que há uma continuidade entre as relações hostis e o fornecimento de prestações recíprocas: as trocas são guerras pacificamente resolvidas, as guerras são a saída de transações infelizes. Como afirma Anspach (2012), essa continuidade entre troca e violência não pode ser direta, pois não se retribui um golpe com um presente. Seria o sacrifício que faria a mediação entre uma reciprocidade baseada no conflito e uma 
troca de dádivas. O sacrifício seria, portanto, o terceiro elemento que tornaria transparente a relação entre os universos de violência e vingança e a dádiva.

Conectando essa discussão teórica sobre vendeta como reciprocidade com os casos aqui em questão, temos reunidos nos universos aqui analisados esse complexo tecido social formado por dádivas, violências, conflitos, afetos e desafetos que, pela via dos sacrifícios daqueles que emigram, quando em relação, compõem a força do dar-receber-retribuir. Ao fim e ao cabo, a relação é a força mágica, é a relação que se estabelece entre os indivíduos, próximos ou distantes, que faz o círculo da reprodução social seguir em seu espiral.

Quando esse círculo se rompe? Quando os indivíduos não são capazes de trocar, quando não mais podem atualizar tais relações.

\section{Reflexões finais}

Desde o início dos anos 2000, esforços têm sido empreendidos no sentido de incluir o gênero como um princípio classificatório que atravessa o movimento migratório e que, juntamente com outras categorias como classe, geração, raça e etnia, configura as oportunidades de migrantes. Este deslocamento se observa no crescente número de estudos que analisam e debatem os fluxos de mulheres privilegiando as discussões sobre rearticulações das relações familiares e de gênero nesses processos.

É neste cenário que se desenvolvem as pesquisas sobre as famílias transnacionais e as teorias sobre o cuidado transnacional, circulação de afeto, co-presença (Baldassar, Wilding, Baldock, 2006; Baldassar, 2008, 2016; Lyon, 2006; Hochschild, 1983; Bryceson, Vuorela, 2002). Os autores destas perspectivas encadeiam de forma direta o aumento das migrações femininas nas últimas décadas com o surgimento das famílias transnacionais e a necessidade destas emigrantes de cuidarem dos que ficaram. A noção de família transnacional ganha força quando, ao olhar para as teorias do cuidado, tais estudiosos se perguntam, como pensar no cuidado a distância?

As novas tecnologias são percebidas como ferramentas poderosas que viabilizam e têm influenciado a troca de cuidado transnacional e a construção da co-presença. Assim, a democratização das chamadas telefônicas, da internet e dos smartphones que permitem que as pessoas se comuniquem online por envio de mensagens, estaria intimamente ligada à possibilidade de criação e manutenção de práticas cotidianas de cuidado entre familiares que compõem tais redes. No caso analisado por mim não é diferente, uma vez que a circulação de cuidado neste contexto migratório é uma evidência e, portanto, uma faceta importante para a compreensão das dinâmicas familiares a distância (Laurent, 2018). 
Entretanto, percebo algumas limitações no caminho analítico que acaba por dar centralidade explicativa às dinâmicas familiares de migrantes pela via da produção de co-presença e dos cuidados a distância. A primeira delas tem a ver com a ordem das coisas. Ao focar nas práticas cotidianas dos cuidados em redes familiares transnacionais, creio que tem ficado em segundo plano dimensões estruturantes das vidas familiares e dos cenários migratórios. Meu ponto é que tais práticas dão vida e atualizam estruturas mais profundas, de longo termo, que atravessam gerações e que estão no cerne dos projetos familiares. Refiro-me, para o caso de Cabo Verde, do caráter estruturante, da profundidade histórica da emigração, vista como um valor, como um destino, como um imponderável. Nesse contexto, as práticas cotidianas de circulação do afeto e do cuidado são índices de um fenômeno que deve ser compreendido mais processualmente, e não reduzidos às esferas de cuidado como se esse fosse o fenômeno em si.

E foi trilhando esse caminho que parti do cuidado para chegar nas omissões e mascaramentos. Se tiramos do centro de nossa atenção o cuidado como prática e ficamos com o conceito teórico de trocas recíprocas como elemento central na feitura do universo familiar nas ilhas, compreendemos a troca como um fator que estrutura relações entendidas como familiares. Feito isso, ampliamos nosso campo analítico e incorporamos o não cuidado como fator que faz relações. Então, aquele que não cuida, que engana ou omite não está fora desse processo, muito antes pelo contrário. As histórias de fracasso, vergonha, esquecimento, abandono e ingratidão compõem, adensam e enriquecem esse universo tanto quanto os cuidados e os afetos.

Mesmo porque os universos de migração não se dão no vácuo, eles operam em uma cartografia global profundamente desigual que insere tanto os migrantes quanto seus familiares na constante gestão de sua condição precária. Não podemos esquecer que na maior parte das vezes, quando tratamos dos casos como aqui abordei, estamos diante de populações que gerem redes sociais e econômicas de apoio que são deficientes e ficam expostas de forma diferenciada às violações, à violência, ao preconceito e ao racismo. Reduzir esse complexo emaranhado, que conecta famílias e estados nacionais, às dinâmicas de cuidado e afeto seria, no mínimo, romantizar as trajetórias.

É, portanto, na tentativa de fugir de formulações teóricas que, apesar de inspiradoras, por vezes simplificam as realidades etnográficas que opto por tratar das interfaces entre gênero, migrações e dinâmicas familiares pela via dos processos e não pela adjetivação de formas familiares, pois creio que acompanhar processos nos permite acessar tanto as práticas cotidianas do fazer família a distância, quanto as estruturas que informam e extrapolam tais práticas em suas interações. Ao incorporar as trajetórias classificadas pela via do insucesso e trazer para o centro da análise as mentiras e segredos, minha 
intenção é de ampliar nossas reflexões, pois como diz o romancista Francisco Azevedo em seu romance Arroz de Palma (2008), "família é prato mesmo delicadíssimo, difícil de preparar".

\section{Referências bibliográficas}

APPADURAI, Arjun. Modernity at Large: Cultural Dimensions of Globalization. Minneapolis: University of Minnesota Press, 1996.

ANSPACH, Mark. Anatomia da Vingança: figuras elementares da reciprocidade. São Paulo: Realizações Editora, 2012.

AZEVEDO, Francisco. Arroz de Palma. Porto: Porto Editora, 2008.

BASCH, Linda; GLICK SCHILLER, Nina; BLANC-SZANTON, Cristina (eds.). Towards a Transnational Perspective on Migration: Race, class, ethnicity and nationalism reconsidered. New York: New York Academy of Sciences, 1992.

BALDASSAR, Loretta. Missing kin and longing to be together: emotions and the construction of co-presence in transnational relationships. Journal of intercultural studies, v. 29, n. 3, p. 247-266, 2008.

BALDASSAR, Loretta. De-demonizing distance in mobile family lives: co-presence, care circulation and polymedia as vibrant matter. Global Networks, n. 16, p. 145-163, 2016.

BALDASSAR, Loretta; WILDING, Raelene; BALDOCK, Cora. Long-distance caregiving, transnational families and the provision of aged care. In: PAOLETTI, Isabella (ed.). Family Caregiving for Older Disabled. New York: Nova Science, 2006.

BRAZ DIAS, Juliana. Entre Partidas e Regressos: tecendo relações familiares em Cabo Verde. Dissertação de Mestrado em Antropologia Social. Universidade de Brasília, 2000.

BONGIANINO, Claudia. Malas de sonhos e saudades: família e mobilidade entre cabo-verdianos na Itália. Dissertação de Mestrado em Antropologia Social. Universidade de Brasília, 2012.

BOURDIEU, Pierre. Le sens pratique. Paris: Les Éditions de Minuit, 1980.

BRYCESON Deborah; VUORELA Ulla (eds.). The Transnational Family. New European Frontiers and Global Networks. Oxford and New York: Berg, 2002.

CARLING, Jorgen. Aspiration and ability in international migration. Cape Verdean Experiences of Mobility and Immobility. Oslo: University of Oslo, 2001.

CARLING, Jorgen. Migration in the age of involuntary immobility: Theoretical reflections on the Cape Verdean experience. Journal of Ethnic and Migration Studies, v. 28, n. 1, p. 5-42, 2002.

CARREIRA, Antonio. Migrações nas ilhas de Cabo Verde. Praia: Instituto CaboVerdiano do Livro, 1983.

CHAMBERLAIN, Mary. Rethinking Caribbean families: extending the links. Community, Work and Family, v. 6, n. 1, p. 63-76, 2003. 
CHAMBERLAIN, Mary. Family love in the diaspora. Migration and the anglocaribbean experience. New Jersey: Transaction Publishers, 2009.

CHAMBERLAIN, Mary; LEYDESDORFF Selma, Transnational families: memories and narratives. Global Networks, v. 4, n. 3, p. 227-241, 2004.

DEFREYNE, Elisabeth. Au rythme des tambor. Ethnographie des mobilités des "gens de Santo Antão" (Cap-Vert, Belgique, Luxembourg). Thèse présentée en vue de I'obtention du grade de Docteure en Sciences Politiques et Sociales: Anthropologie, 2016.

GLICK SCHILLER, Nina, The Centrality of ethnography in the study of transnational migration: seeing the wetland instead of the swamp. In: FONER, Nancy (ed.). American Arrivals. Santa Fe, NM: School of American Research, 2003.

GLICK SCHILLER, Nina; FOURON, Georges. Terrains of Blood and Nation: Haitian Transnational Social Fields. Ethnic and Racial Studies, v. 22, n. 2, p. 340-366, 1999. HOCHSCHILD, Arlie. The Managed Heart. Commercialization of Human Feeling. Berkeley: University of California Press, 1983.

LAURENT, Pierre-Joseph. Amours Pragmatiques. Familles, Migrations et sexualité au Cap-Vert aujourd'hui. Paris: Karthal, 2018.

LEVITT, Peggy; GLICK SCHILLER, Nina. Conceptualizing Simultaneity: A Transnational Social Field Perspective on Society. International Migration Review, v. 38, n. 3, p. 1002-1039, 2004.

LOBO, Andréa. Um filho para duas mães? Notas sobre a maternidade em Cabo Verde. Revista de Antropologia da USP, v. 53, n. 1, p. 117-145, 2010.

LOBO, Andréa. Making Families: Child mobility and familiar organization in Cape Verde. Vibrant. Virtual Brazilian Anthropology, v. 8, n. 2, p. 197-219, 2011.

LOBO, Andréa. Entre Fluxos. Brasília: Editora da UnB, 2012a.

LOBO, Andréa. Vidas em Movimento. Sobre mobilidade infantil e emigração em Cabo Verde. In: DIAS, Juliana; LOBO, Andréa (eds.). África em Movimento. Brasília: ABA Publicações, 2012 b.

LOBO, Andréa. Crianças em cena. Sobre mobilidade infantil, família e fluxos migratórios em Cabo Verde. Revista de Ciências Sociais Unisinos, v. 49, n. 1, p. 64-74, 2013.

LOBO, Andréa. Tão longe e tão perto: famílias e "movimentos" na Ilha da Boa Vista de Cabo Verde. Revised ed. E-Book. Brasília: ABA Publicações, 2014a.

LOBO, Andréa. "Just bring me a little letter": the flow of things in Cape Verde transnational family relations. Etnográfica, v. 18, n. 3, p. 461-480, 2014 b.

LYON, Dawn. The Organization of Care Work in Italy: Gender and Migrant Labor in the New Economy. Indiana Journal of Global Legal Studies, v. 13, n. 1, p. 207224, 2006.

MEINTEL, Deirdre. Emigração em Cabo Verde: solução ou problema. Revista Internacional de Estudos Africanos, v. 2, p. 93-120, 1984.

MEINTEL, Deirdre. Cape Verdean transnationality, old and new. Anthropologica, v. XLIV, n. 1, p. 25-42, 2002. 
MONTEIRO, Maria Ivone. Família e género na perspectiva das mulheres kumbóssas: um estudo etnográfico no Concelho de Santa Catarina, Ilha de Santiago/CV. Dissertação de Mestrado em Ciências Sociais. Universidade de Cabo Verde UniCV, 2013.

MOUDILENO, Lydie. La fiction de la migration: manipulation des corps et des récits dans Bleu blanc rouge d'Alain Mabanckou. Présence Africaine, v. 1, n. 163164, p. 182-189, 2001.

PARREÑAS, Raquel. Children of Global Migration. Transnational families and gendered woes. California: Standford University Press, 2005.

SIMMEL, Georg. The Secret and Secret Society. In: SIMMEL, Georg. The Sociology of Georg Simmel. Nova York: The Free Press, 1964.

SIMMEL, Georg. A sociologia do segredo e das sociedades secretas. Trad. de Simone Carneiro Maldonado. Revista de Ciências Humanas, v. 43, n. 1, p. 219242, 2009.

TEIXEIRA, Carla Costa. Pesquisando instâncias estatais: reflexões sobre o segredo e a mentira. In: CASTILHO, Sérgio Ricardo Rodrigues; SOUZA LIMA, Antonio Carlos de; TEIXEIRA, Carla Costa (orgs.). Antropologia das práticas de poder: reflexões etnográficas entre burocratas, elites e corporações. Rio de Janeiro: Contra Capa - Faperj, 2014, p. 33-42.

TRAJANO FILHO, Wilson. The Conservative Aspects of a Centripetal Diaspora: the case of the Cape Verdean Tabancas. Africa, v. 79, n. 4, p. 520-542, 2009.

VASCONCELOS, João. "Manera, ess muv?": a mobilidade como valor em São Vicente de Cabo Verde. In: DIAS, Juliana; LOBO, Andréa (eds.). África em Movimento. Brasília: ABA Publicações, 2012.

VEIGA, Maria Anilda Martins. (Re)configuração identitária das mulheres cujos maridos/companheiros emigraram: uma análise a partir das mulheres de PilãoCão. Dissertação de Mestrado em Ciências Sociais. Universidade de Cabo Verde, UniCV, 2013.

VIANA, Alba; SOUSA, Eduardo. Crimes e segredos na violência sexual contra as mulheres: o diálogo entre Durkheim e Simmel. Política \& Sociedade, v. 14, n. 29, p. 11-29, 2015.

WEST, Candace; FENSTERMAKER, Sarah. Doing Difference, Gender and Society, v. 9, n. 1, p. 8-37, 1995. 